\title{
BINARY: an optical freezing array for assessing temperature and time dependence of heterogeneous ice nucleation
}

\author{
C. Budke and T. Koop \\ Faculty of Chemistry, Bielefeld University, Universitätsstraße 25, 33615 Bielefeld, Germany \\ Correspondence to: T. Koop (thomas.koop@uni-bielefeld.de)
}

Received: 23 August 2014 - Published in Atmos. Meas. Tech. Discuss.: 10 September 2014

Revised: 23 December 2014 - Accepted: 20 January 2015 - Published: 10 February 2015

\begin{abstract}
A new optical freezing array for the study of heterogeneous ice nucleation in microliter-sized droplets is introduced, tested and applied to the study of immersion freezing in aqueous Snomax ${ }^{\circledR}$ suspensions. In the Bielefeld Ice Nucleation ARraY (BINARY) ice nucleation can be studied simultaneously in 36 droplets at temperatures down to $-40^{\circ} \mathrm{C}(233 \mathrm{~K})$ and at cooling rates between 0.1 and $10 \mathrm{~K} \mathrm{~min}^{-1}$. The droplets are separated from each other in individual compartments, thus preventing a Wegener-Bergeron-Findeisen type water vapor transfer between droplets as well as avoiding the seeding of neighboring droplets by formation and surface growth of frost halos. Analysis of freezing and melting occurs via an automated real-time image analysis of the optical brightness of each individual droplet. As an application ice nucleation in water droplets containing Snomax ${ }^{\circledR}$ at concentrations from $1 \mathrm{ng} \mathrm{mL}^{-1}$ to $1 \mathrm{mg} \mathrm{mL}^{-1}$ was investigated. Using different cooling rates, a small time dependence of ice nucleation induced by two different classes of ice nucleators (INs) contained in Snomax ${ }^{\circledR}$ was detected and the corresponding heterogeneous ice nucleation rate coefficient was quantified. The observed time dependence is smaller than those of other types of INs reported in the literature, suggesting that the BINARY setup is suitable for quantifying time dependence for most other INs of atmospheric interest, making it a useful tool for future investigations.
\end{abstract}

\section{Introduction}

Atmospheric ice nucleation is one of the key steps in highaltitude cloud formation and also for triggering precipitation in mixed-phase clouds (Pruppacher and Klett, 1997; Cantrell and Heymsfield, 2005; Lamb and Verlinde, 2011). Ice particles can be formed via homogeneous ice nucleation in liquid aerosol and water droplets (Koop et al., 2000; Murray et al., 2010), or via heterogeneous ice nucleation triggered by preexisting ice nucleators (Pruppacher and Klett, 1997; Cantrell and Heymsfield, 2005; DeMott et al., 2010; Murray et al., 2012; Hoose and Möhler, 2012; Cziczo and Froyd, 2014). Both homogeneous as well as heterogeneous ice nucleation processes do occur, and various approaches of parameterizing them in atmospheric models have been described. One strategy for improving the description of ice nucleation in cloud models is the elucidation of the responsible mechanisms and their physical dependencies in laboratory experiments. For example, such laboratory data can then serve as a basis for physically consistent parameterizations for heterogeneous ice nucleation that can be incorporated into process models (Hoose and Möhler, 2012). In mixed-phase clouds heterogeneous immersion mode freezing is thought to be a relevant process (Pruppacher and Klett, 1997; Lohmann and Diehl, 2006). But time dependence of immersion freezing is often poorly represented or not included at all in cloud models, in order to reduce model complexity (Ervens and Feingold, 2012). It is well accepted that homogeneous ice nucleation is a time-dependent stochastic process which can be described by the formation of an ice embryo with critical size, whose probability of forming increases with time (Pruppacher and Klett, 1997; Murray et al., 2010; Riechers et al., 2013). There is, however, an ongoing debate on whether heterogeneous ice nucleation in the immersion mode is only 
temperature dependent (i.e., a singular process) or both temperature and time dependent (i.e., a stochastic process) (Vali, 2014). In a stochastic process, the probability of the occurrence of a nucleation event increases exponentially with time at a rate that depends on temperature (e.g., Bigg, 1953; Vonnegut and Baldwin, 1984; Pruppacher and Klett, 1997; Vali, 1994, 2014). In contrast, in a singular process no such time dependence of ice nucleation exists, because the probability of ice nucleation switches instantaneously from 0 to 1 at a deterministic temperature that depends on the IN (e.g., Vali and Stansbury, 1966). Moreover, another so-called modified singular process has been proposed that describes the overall process as temperature dependent with a small stochastic variation around the deterministic temperature (Vali, 2008).

Several studies have employed experimental data and model calculations to show very little time dependence, thus justifying the use of the time-independent singular approach (Kulkarni et al., 2012; Welti et al., 2012; Wright and Petters, 2013; Ervens and Feingold, 2013; Vali, 2014). But it has been also suggested that any existing small time dependence should not be neglected if a more accurate description of heterogeneous nucleation is to be achieved in models (Barahona, 2012; Knopf and Alpert, 2013; Vali and Snider, 2014). One drawback from which many experimental techniques suffer is the fact that cooling rates or the rates by which the supersaturation changes can be varied over a small range only, thus limiting their sensitivity to distinguish between the different approaches (see, e.g., the discussion in Niedermeier et al., 2010; Lüönd et al., 2010).

Several instrumental techniques are available for the determination of temperature and time dependence of heterogeneous ice nucleation (see, e.g., Murray et al., 2012; Hoose and Möhler, 2012). One of the commonly used methods is based on an early description of a drop-freezer apparatus developed by Vali and Stansbury (1966) and Vali (1971a). In the original setup, microliter-sized droplets are pipetted onto a substrate that is placed on a thermoelectric cooler. The droplets are separated by about $1 \mathrm{~cm}$ from each other, but no other precautions are taken to avoid a Wegener-BergeronFindeisen type process, i.e., the growth of frozen droplets at the expense of remaining supercooled liquid ones by water vapor transfer. In addition, the latent heat release during freezing may cause the formation of frost halos that subsequently may grow and expand around the frozen droplets by Wegener-Bergeron-Findeisen type water vapor transfer (Jung et al., 2012; Welz, 2013). This frost halo growth bears the risk of seeding neighboring droplets and thus biasing the recorded ice nucleation temperatures (Jung et al., 2012; Welz, 2013). To circumvent these problems and to minimize evaporation, droplets are often covered with an oil film (Bigg, 1953; Hoffer, 1961; Murray et al., 2011; Pummer et al., 2012; Wright and Petters, 2013). But the use of such emulsion-type samples may lead to alternative problems because some ice nucleators (INs) such as pollen or fungal spores may have an affinity to the hydrophobic phase. When a part of the dis- persed IN material is lost to the oil phase, an overestimation of IN concentration may result, leading to an underestimation of IN activity. Another uncertainty arises if surfactants are used for the stabilization of emulsions, because surfactants may also influence the investigated INs at the water-oil interface (Pummer et al., 2012), particularly when the INs reside predominantly at the droplet surface.

A very recent instrument development of Stopelli et al. (2014) uses sealable tubes to prevent evaporation and crosscontamination of the investigated suspensions. The device bears an additional advantage over previous tube-based ice nucleation devices (e.g., Barlow and Haymet, 1995; Heneghan et al., 2002) in that it allows simultaneous investigation of multiple samples rather than focusing on numerous freeze-thaw repeats of a limited number of samples.

Another improvement is the nature of the substrate on which the droplets are positioned. In the original drop freezer, water droplets were pipetted onto an oil-covered sheet of aluminum foil (Vali and Stansbury, 1966). More recent techniques make use of advanced chemical approaches to hydrophobize glass or quartz substrates by a selfassembled monolayer (e.g., using a halogenated silane), which does not affect the mechanical or thermal properties of the substrate (Koop et al., 1998; Salcedo et al., 2000; Knopf and Lopez, 2009; Murray et al., 2010; Iannone et al., 2011).

Some of the devices introduced in the past for the analysis of heterogeneous ice nucleation employ rather large sample volumes (tens to hundreds of microliters) in order to be able to further analyze the ice-nucleating substances, for longterm IN sample storage and an associated investigation of ageing effects, or to ease the detection of freezing (Barlow and Haymet, 1995; Attard et al., 2012; Stopelli et al., 2014). Others have focused on rather small (often emulsified) samples (picoliters to nanoliters) in order to minimize or exclude the unwanted effects of ice-nucleating impurities contained in the water for preparing the suspensions under scrutiny (Koop and Zobrist, 2009; Murray et al., 2010, 2011; Pummer et al., 2012; Wright and Petters, 2013; Atkinson et al., 2013). Herein we use intermediate volume samples of $1 \mu \mathrm{L}$ which are easy to prepare and are not subject to concentration uncertainties owing to water evaporation during sample preparation and storage. For such volumes heterogeneous ice nucleation from impurities contained in the "pure" water usually occurs at temperatures below $-20^{\circ} \mathrm{C}(253 \mathrm{~K})$. Therefore, such samples are applicable for ice nucleation studies over the important temperature range of mixed-phase clouds between $-20^{\circ} \mathrm{C}(253 \mathrm{~K})$ and $0{ }^{\circ} \mathrm{C}(273 \mathrm{~K})$. At lower temperatures, corrections for the effects of IN impurities contained in "pure" water must be employed.

In the following, we introduce a new droplet freezing assay, in which the separation of the investigated water droplets is accomplished by a polymer spacer. This spacer encloses each of a total of 36 microliter-sized droplets individually without direct contact to any of them. Moreover, we have developed an automated system for analyzing the freezing 
temperature of each drop. Finally, the device allows for an accurate determination of ice nucleation temperatures over a large range of cooling rates from 0.1 to $10 \mathrm{~K} \mathrm{~min}^{-1}$. We chose Snomax ${ }^{\circledR}$, a commercially available ice inducer used in snow cannons, as a test substance for the investigation of heterogeneous ice nucleation and an assessment of its temperature and time dependence.

\section{Theoretical background for freezing analysis}

\subsection{Singular (deterministic) data analysis}

The temperature dependence of ice nucleation induced by singular ice nucleators can be described in terms of $n_{\mathrm{m}}(T)$, the cumulative number of ice nucleators per mass of Snomax ${ }^{\circledR}$ as a function of temperature. $n_{\mathrm{m}}(T)$ can be obtained from droplet freezing array data by analyzing the frozen fraction $f_{\text {ice }}$ from the cumulative number of frozen droplets $n_{\text {ice }}(T)$ and the total number of droplets $n_{\text {tot }}$ of a particular Snomax ${ }^{\circledR}$ concentration (Vali, 1971b):

$f_{\text {ice }}(T)=\frac{n_{\text {ice }}(T)}{n_{\text {tot }}}=1-e^{-K(T) V}$.

From Eq. (1) the cumulative ice nucleator concentration $K(T)$ can be deduced, which is typically referred to as the active site number density per unit droplet volume $V$. Because in the experiments described below we know the mass concentration $C_{\mathrm{m}}$ of Snomax ${ }^{\circledR}$ and the volume $V$ of the droplets, $K(T)$ can be converted into the active site density per unit mass $n_{\mathrm{m}}(T)$ :

$n_{\mathrm{m}}(T)=\frac{K(T)}{C_{\mathrm{m}}}=n_{\mathrm{s}}(T) \cdot S^{\prime}=n_{\mathrm{n}}(T) \cdot N^{\prime}$.

Likewise the active site density per unit surface area $n_{\mathrm{s}}(T)$ or per particle number $n_{\mathrm{n}}(T)$ can be deduced if the specific surface area $S^{\prime}$, i.e., the surface area per sample mass, or the specific particle number $N^{\prime}$, i.e., the number of particles per sample mass, respectively, are known from independent analysis (Fletcher, 1969; Connolly et al., 2009; Murray et al., 2012; Niemand et al., 2012).

The value of the specific surface area $S^{\prime}$ of Snomax ${ }^{\circledR}$ can be derived as follows. For the specific particle number of cells in Snomax ${ }^{\circledR}$ we used the value of $N^{\prime}=1.4 \times 10^{9} \mathrm{mg}^{-1}$ determined by Wex et al. (2015) using multiple instruments including the BINARY setup presented here. Furthermore, Wex et al. (2015) investigated the size of the particles/cells suspended in freshly prepared Snomax ${ }^{\circledR}$ suspensions by dynamic light scattering, resulting in a mean equivalent hydrodynamic radius of $r_{\mathrm{h}}=0.5 \mu \mathrm{m}$. Accordingly, we assumed that each cell has a surface area equivalent to that of a sphere with a radius of $0.5 \mu \mathrm{m}$, i.e., a surface area of $3.14 \mu \mathrm{m}^{2}$ per cell. These numbers result in a value of $S^{\prime}=44 \mathrm{~cm}^{2} \mathrm{mg}^{-1}$, which was used here.

\subsection{Time-dependent (stochastic) data analysis}

A time dependence of ice nucleation induced by ice nucleators can be investigated by performing freezing experiments at different cooling rates in order to determine the nucleation rate $R(T)$. For such experiments, temperature is divided into equally spaced intervals $\Delta T=T_{1}-T_{2}=0.1 \mathrm{~K}$ and all data are binned into these temperature intervals with interval temperature $T=T_{1}-0.5 \cdot \Delta T$. When droplets are cooled at a constant cooling rate $\beta$, the nucleation rate $R(T)$ at the interval temperature $T$ can be derived from the number of droplets nucleated in that interval $\Delta n_{\text {ice }}(T)$ (Vali, 1994; Koop et al., 1997; Zobrist et al., 2007):

$$
\begin{aligned}
R(T) & =\frac{\Delta n_{\mathrm{ice}}(T)}{t_{\mathrm{tot}}(T)} \\
& =\frac{\Delta n_{\mathrm{ice}}(T) \cdot \beta}{\Delta T \cdot\left(n_{\mathrm{liq}}\left(T_{1}\right)-\Delta n_{\mathrm{ice}}(T)\right)+\sum_{j=1}^{\Delta n_{\mathrm{ice}}(T)}\left(T_{1}-T_{\mathrm{nuc}, j}\right)},
\end{aligned}
$$

where $j=1, \ldots, \Delta n_{\text {ice }}(T)$ are the nucleation events in individual droplets occurring at temperature $T_{\text {nuc, } j}$ within the interval $\Delta T$. With the simplification $T_{\text {nuc, } j} \approx T_{1}-0.5 \cdot \Delta T$, which is a good approximation for small temperature intervals, the sum in the denominator in Eq. (4) can be approximated by $0.5 \cdot \Delta T \cdot \Delta n_{\text {ice }}(T)$ and, hence,

$R(T) \approx \frac{\Delta n_{\mathrm{ice}}(T) \cdot \beta}{\Delta T \cdot\left(n_{\mathrm{liq}}\left(T_{1}\right)-0.5 \cdot \Delta n_{\mathrm{ice}}(T)\right)}$.

Data of $R(T)$ can be normalized to the total surface area of ice nucleator per droplet $A$, which for the case of a singlecomponent (sc) ice nucleator is equivalent to the nucleation rate coefficient $j_{\text {het }}(T, \alpha)$,

$\frac{R(T)}{A}=\frac{R(T)}{S^{\prime} C_{\mathrm{m}} V} \stackrel{\text { sc }}{=} j_{\text {het }}(T, \alpha)$,

with the parameters $S^{\prime}, C_{\mathrm{m}}$ and $V$ as defined above. Using the framework of classical nucleation theory $(\mathrm{CNT}) j_{\text {het }}(T, \alpha)$ can be described as (Pruppacher and Klett, 1997)

$$
\begin{aligned}
j_{\text {het }}(T, \alpha) & =\frac{k T}{h} \exp \left(-\frac{\Delta F_{\text {diff }}(T)}{k T}\right) \\
& \cdot n \exp \left(-\frac{\Delta G(T) \varphi(\alpha)}{k T}\right) .
\end{aligned}
$$

Here $k$ is the Boltzmann constant, $h$ is the Planck constant, $T$ is absolute temperature and $n$ is the number density of water molecules at the IN-water interface. $\Delta F_{\text {diff }}(T)$ and $\Delta G(T)$ are the diffusion activation energy of a water molecule crossing the water-ice embryo interface and the Gibbs free energy for critical ice embryo formation without the presence of a heterogeneous IN, respectively. In the presence of an 
ice nucleus $\Delta G(T)$ is modified by the compatibility function $\varphi(\alpha)$ :

$\varphi(\alpha)=\frac{1}{4}(2+\cos \alpha)(1-\cos \alpha)^{2}$,

where the parameter $\alpha$ represents a hypothetical effective contact angle between the forming ice embryo and the IN in water, which can vary between 0 and $180^{\circ}$. An effective contact angle of $\alpha=0^{\circ}$ implies a perfect IN leading to $\varphi=0$ and a negligible Gibbs free energy term (equivalent to seeding by a mother crystal). An effective contact angle of $\alpha=180^{\circ}$ leads to $\varphi=1$, and the Gibbs free energy term is not reduced, implying a maximally poor IN; thus, nucleation occurs at the rate of homogeneous ice nucleation. For our analysis of $j_{\text {het }}(T, \alpha)$ from experimental data we use $\alpha$ as the only free parameter when fitting Eq. (7) to the data. Temperature-dependent parameterizations for all other quantities were obtained from Zobrist et al. (2007).

\subsection{Quantification of time dependence}

In a very recent study Herbert et al. (2014) proposed the following equation for the description of cooling rate dependence of a single IN (applied to $T_{\mathrm{f}, 50}$ values here):

$T_{\mathrm{f}, 50}\left(\beta_{2}\right)-T_{\mathrm{f}, 50}\left(\beta_{1}\right)=\Delta T_{\mathrm{f}, 50}=\frac{1}{\lambda} \cdot \ln \left(\frac{\beta_{1}}{\beta_{2}}\right)$.

$T_{\mathrm{f}, 50}\left(\beta_{2}\right)$ and $T_{\mathrm{f}, 50}\left(\beta_{1}\right)$ are the median freezing temperatures at cooling rates $\beta_{2}$ and $\beta_{1}$, respectively, and $\lambda$ is a constant. Herbert et al. (2014) point out that, for a single-component IN following stochastic (i.e., non-singular) behavior, $\lambda$ is the temperature dependence of the heterogeneous ice nucleation rate coefficient of the IN: $\lambda=-\mathrm{d} \ln \left(j_{\text {het }}\right) / \mathrm{d} T$. We note that an equation similar to Eq. (9) was originally introduced by Vali and Stansbury (1966) for the mean freezing temperature, i.e., $\bar{T}_{\mathrm{f}}\left(\beta_{2}\right)-\bar{T}_{\mathrm{f}}\left(\beta_{1}\right)=\xi \cdot \ln \left(\frac{\beta_{1}}{\beta_{2}}\right)$. Ignoring any difference between $\bar{T}_{\mathrm{f}}$ and $T_{\mathrm{f}, 50}$ (which occurs, e.g., for a $T_{\mathrm{f}}$ distribution that is constant with changing cooling rate) implies that the constant $\xi$ is related to $\lambda$ via $\xi=\lambda^{-1}$. For the singular case $\xi_{\mathrm{si}}=0$ and $\lambda_{\mathrm{si}}=\infty$ by definition, and a small $\xi /$ large $\lambda$ value indicates a behavior that is close to singular; i.e., nucleation shows a less-pronounced stochastic time dependence. Moreover, one can define the temperature dependence of the normalized freezing rate $\omega=-\mathrm{d} \ln (R / A) / \mathrm{d} T$ and note that $\omega=\lambda$ for a single-component IN and $\omega<\lambda$ for a multi-component IN (Vali, 2014; Herbert et al., 2014).

\section{Experimental setup}

The optical freezing apparatus introduced here, which we term BINARY (Bielefeld Ice Nucleation ARraY), consists of a $6 \times 6$ array of individual microliter-sized droplets positioned on a thin hydrophobic glass slide (Fig. 1a). The droplets are separated from each other by a soft polydimethylsiloxane (PDMS) spacer, and the resulting compartments are sealed at the top with another glass slide (Fig. 1b). The PDMS spacer is fabricated from a 10:1 mixture of base polymer to curing agent (Sylgard ${ }^{\circledR} 184$, Dow Corning) poured onto a mold made from aluminum that was customdesigned to represent the compartment array.

The droplet separation into individual compartments prevents a Wegener-Bergeron-Findeisen process, in which frozen droplets grow at the expense of unfrozen supercooled liquid droplets due to the vapor pressure difference between ice and supercooled liquid water (Murphy and Koop, 2005). This process poses a particular problem to droplet arrays operated at small cooling rates or employing stepwise cooling and has been noted frequently to influence and corrupt ice nucleation measurements (Welz, 2013; Stopelli et al., 2014; O'Sullivan et al., 2014). In addition, the probability of heterogeneous ice nucleation at the lower glass surface is minimized by the hydrophobicity of the glass (see discussion above). Water droplets positioned on the silanized glass show contact angles of about $90-100^{\circ}$ (Remmers, 2012). Hence, the shape of the droplets investigated below is well approximated by a hemisphere.

Snomax ${ }^{\circledR}$ suspensions were prepared by mixing a predetermined mass of dry material with the appropriate volume of freshly double-distilled water. Individual droplets of $1 \mu \mathrm{L}$ volume were sampled from the suspension with a micropipette (volume inaccuracy $\leq 3 \%$ ) and positioned individually on the glass surface in each compartment. We note that the use of smaller (e.g., $\sim 0.5 \mu \mathrm{L}$ ) and larger (e.g., $\sim 5 \mu \mathrm{L}$ ) droplets is also possible, but only $1 \mu \mathrm{L}$ droplets were used in the freezing experiments described below.

The sample array is placed onto a Peltier cooling stage (Fig. 1c), which is part of a commercially available cooling stage system (Linkam LTS120). Good thermal contact between the Peltier stage and the lower glass surface of the sample array is achieved by pressing the upper glass slide towards the stage with four fixing screws, one at each corner. When the Peltier stage is connected to a heat sink bath at $5{ }^{\circ} \mathrm{C}(278 \mathrm{~K})$, the sample array can be cooled to $-40{ }^{\circ} \mathrm{C}$ $(233 \mathrm{~K})$ at cooling rates between 0.1 and $10 \mathrm{~K} \mathrm{~min}^{-1}$. The cover of the cooling stage was modified to consist of a larger opening sealed with a thin glass window such that the resulting larger field of view of $40 \mathrm{~mm} \times 40 \mathrm{~mm}$ allowed for the simultaneous observation of all droplets of the sample array. In addition, small arrays of cold-light white LEDs were fixed to the top of the cooling chamber to yield the proper contrast for identifying the phase state of the droplets; see below. Finally, purging of dry $\mathrm{N}_{2}$ gas into the chamber as well as onto the top window prevents dew and frost formation from laboratory humidity during cooling.

A LabVIEW $^{\mathrm{TM}}$ virtual instrument is used to control the temperature of the Peltier stage and to analyze in real time the digital images obtained by a CCD camera (QImaging MicroPublisher 5.0 RTV). The images are recorded and an- 
(a) sample array top view

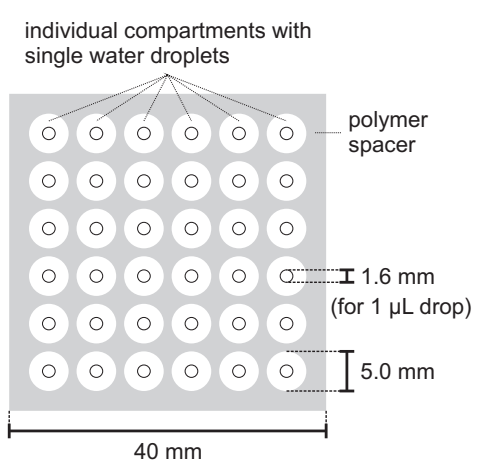

(b) sample array side view

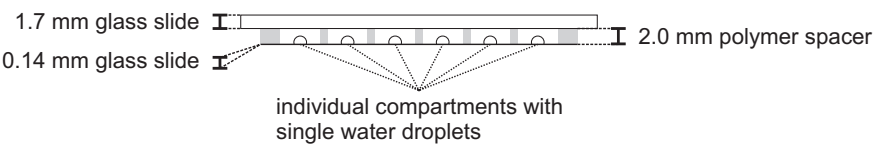

(c) cooling chamber

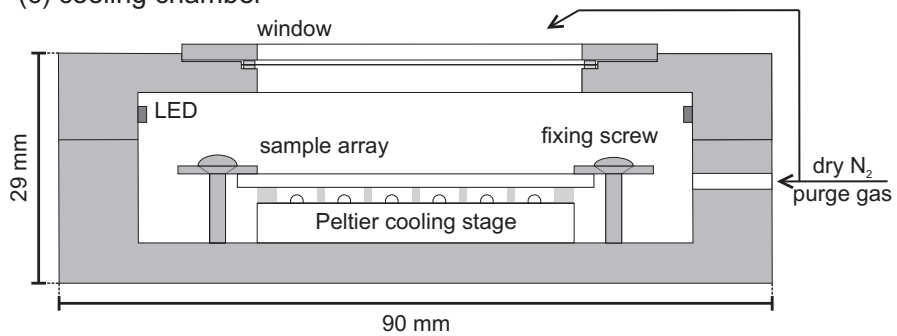

Figure 1. Schematic of the Bielefeld Ice Nucleation ARraY (BINARY) setup. (a) Top view of the $6 \times 6$ droplet array. The droplets are separated from each other by a polymer spacer creating individual compartments. (b) Side view showing the sealing of the compartments by top and bottom glass slides. (c) Position of the sample array on the Peltier cooling stage inside the cooling chamber.

alyzed at a frequency that depends upon the experimental cooling rate: three successive images are analyzed per $0.1 \mathrm{~K}$ temperature interval, i.e., one image every $0.0 \overline{3} \mathrm{~K}$. For example, the corresponding time interval $\left|\Delta t_{j-1, j}\right|$ between successive images $j-1$ and $j$ at a cooling rate of 1 and $5 \mathrm{~K} \mathrm{~min}^{-1}$ is 2 and $0.4 \mathrm{~s}$, respectively. Moreover, every third image is stored in digital format, allowing for later reexamination or re-analysis. These images have a temperature resolution of $0.1 \mathrm{~K}$.

Ice nucleation is determined optically based on the change in droplet brightness when the initially transparent liquid droplets become opaque upon freezing (see Fig. 2a and the video of this experiment available in the Supplement). Since we observe the droplets in reflection mode (not in transmission), in the images liquid droplets appear dark, and frozen droplets appear bright as they scatter light into the observation light path. This change in brightness is maximized by illuminating the droplets by LEDs at a low sideway angle from the top (see Fig. 1c) and also by the reflective top surface of the Peltier stage. The 8 bit mean gray value, gv, (ranging from $\mathrm{gv}=0$ for black to $\mathrm{gv}=255$ for white) is determined for each compartment/droplet $i$ in every image $j$. The difference in gv between successive images and, hence, temperatures $\Delta \mathrm{gv}_{i, j}(T)=\mathrm{gv}_{i, j}-\mathrm{gv}_{i, j-1}$ is then used to determine droplet freezing and melting.

Figure 2 shows an example experiment of water droplets containing Snomax ${ }^{\circledR}$ at a concentration of $0.1 \mu \mathrm{g}$ drop $^{-1}$. In panel a three images are shown of the entire array during cooling. At $-3.5^{\circ} \mathrm{C}(269.6 \mathrm{~K})$ all droplets are still liquid as recognized by their dark appearance, and at $-5.5^{\circ} \mathrm{C}$ $(267.6 \mathrm{~K})$ all droplets are frozen and bright. At the intermediate temperature of $-4.5^{\circ} \mathrm{C}(268.6 \mathrm{~K})$ some bright spots indicate frozen or currently freezing droplets. In panel $\mathrm{b}$ a more detailed analysis is exemplified for the droplet shown in the yellow box in panel a. The droplet is first cooled and subsequently reheated at rates of $1 \mathrm{Kmin}^{-1}$. The mean gray value gv for the droplet is determined from all pixels contained in the yellow box. In the beginning the gray value increases only slightly during cooling, due to condensation of water vapor contained in the compartment onto the bottom glass plate. ${ }^{1}$ Ice nucleation in the droplet occurs at $-3.9^{\circ} \mathrm{C}$ $(269.3 \mathrm{~K})$, resulting in a steep increase of the gray value from about 30 to nearly 70 at $-4.2^{\circ} \mathrm{C}(269.0 \mathrm{~K})$ in the few subsequent images. While the largest gray value change $\Delta \mathrm{gv}$ between two consecutive images is about 10 at a temperature slightly below $-4{ }^{\circ} \mathrm{C}$ ( $269 \mathrm{~K}$; see Fig. 2c for comparison), nucleation and freezing is detected already a few images before. We set a threshold value of $\Delta \mathrm{gv}>1$ for the automatic attribution of ice nucleation, since all other $\Delta \mathrm{gv}$ values during the entire cooling procedure are significantly smaller than 1 at a typical noise level of $\Delta \mathrm{gv} \lesssim \pm 0.2$ (Fig. $2 \mathrm{c}$ ).

Following droplet freezing the previously condensed liquid water then evaporates and freezes onto the frozen droplet, leading to the formation of a frost halo and a slow decrease in gv to about 62 in this particular case (Fig. 2b). After a temperature of $-10^{\circ} \mathrm{C}$ is reached, the sample is reheated. The gray value slightly decreases further since the polycrystalline ice slowly recrystallizes, thus reducing the amount of

\footnotetext{
${ }^{1}$ The condensing water originates from the humidity inside each compartment from the vapor pressure of the droplet itself. At the start of the experiment the relative humidity in each compartment is $100 \%$, and, upon cooling, some of this humidity condenses onto the cold glass slide. These droplets are much smaller than the investigated droplets and, thus, normally freeze at much colder temperature, i.e., at about the homogeneous ice nucleation limit of supercooled water. Therefore, the condensed droplets do not affect the heterogeneous ice nucleation processes in the microliter droplets studied here. Only if heterogeneous ice nucleation is triggered in the condensed droplets (e.g., by a surface impurity/irregularity) might they subsequently seed the larger droplets. This was observed to occur only rarely at the lowest cooling rates, and, accordingly, these data points were excluded from the analysis.
} 
(a)
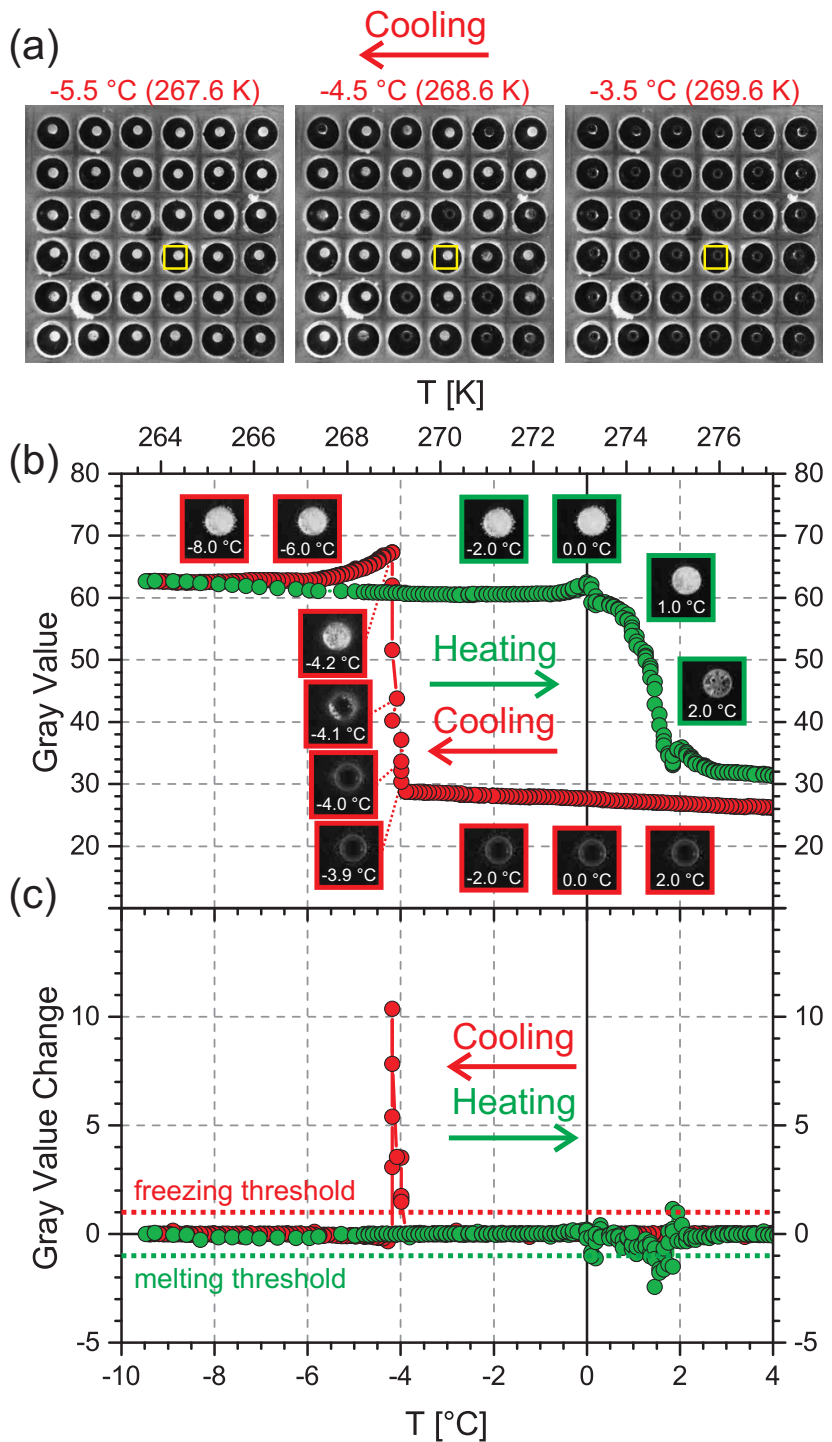

Figure 2. Example experiment with Snomax ${ }^{\circledR}$-containing droplets $\left(0.1 \mu \mathrm{gdrop}^{-1}\right)$ describing the automatic detection of nucleation events by the change in brightness during freezing. A video of this experiment is available in the Supplement. (a) Image series of the $6 \times 6$ droplet array during cooling. (b) Measured gray value of the compartment/droplet indicated by the yellow box in panel (a) during cooling (red) and heating (green). Freezing and melting start at $-3.9^{\circ} \mathrm{C}(269.3 \mathrm{~K})$ and $0.0^{\circ} \mathrm{C}(273.2 \mathrm{~K})$, respectively. (c) Plot of the change in gray value between successive images showing peaks at the phase transition points. Threshold values of \pm 1 for the automatic attribution of freezing and melting are indicated by dashed lines.

ice facets capable of scattering the LED light. Finally, gv increases just before reaching the melting point due to formation of liquid water films in the grain boundaries of the frozen droplet; thus LED light is reflected slightly more efficiently. The onset of melting at $0{ }^{\circ} \mathrm{C}(273 \mathrm{~K})$, most easily observed at the halo, finally results in a decrease of $\mathrm{gv}$ and hence a lo- cal minimum in $\Delta \mathrm{gv}$; see Fig. 2c. We set a threshold value of $\Delta \mathrm{gv}<-1$ for automatic attribution of melting. We note that at a heating rate of $1 \mathrm{~K} \mathrm{~min}^{-1}$ the melting of the entire droplet is complete at about $2{ }^{\circ} \mathrm{C}(275 \mathrm{~K})$.

The analysis described in Fig. 2 is performed automatically for all droplets of a particular array. The nucleation temperatures thus obtained for each droplet undergo a correction according to a temperature calibration that is outlined in the next section.

\section{Temperature calibration}

The experiment discussed in the previous section was performed at a constant cooling rate of $1 \mathrm{~K} \mathrm{~min}^{-1}$. Investigation of time dependence of heterogeneous ice nucleation in such constant cooling rate experiments requires performing several experiments at different cooling rates (see, e.g., Herbert et al., 2014). Therefore, we conducted a comprehensive calibration exercise that accounts for variable cooling rates in BINARY. The calibration was performed using five reference phase transitions in the temperature range of interest from -37 to $0{ }^{\circ} \mathrm{C}$ ( 236 to $273 \mathrm{~K}$; see Table A1 and Fig. A1 in the Appendix) and for heating rates from 0.1 to $10 \mathrm{~K} \mathrm{~min}^{-1}$. The rate calibration was conducted in the heating mode because superheating of a crystal above its melting point is usually negligible. In contrast, supercooling of a liquid below the melting point often occurs readily, and even minor supercooling would bias a calibration in cooling mode (Sarge et al., 2000; Della Gatta et al., 2006). For the solid-liquid phase transition of tridecane the rate dependence of cooling vs. heating was investigated. Although crystal nucleation temperatures of tridecane droplets in the size range from 0.1 to $1.5 \mu \mathrm{L}$ scattered significantly more - by about $0.8 \mathrm{~K}$ between the 25 th to 75 th percentiles - than those of the melting temperatures during calibration - about $0.2 \mathrm{~K}$ - the observed dependence of nucleation temperatures with increasing cooling rate was similar to that of the melting temperatures with increasing heating rate, which were $\sim 0.02$ and $\sim 0.05 \mathrm{~min}$, respectively.

For the calibration procedure the reference substances were sprayed onto the hydrophobic glass slide, resulting in droplets $\sim 0.6 \mathrm{~mm}$ in size (estimated droplet volume about $0.05 \mu \mathrm{L}$ ). The onset of melting and the subsequent, almostimmediate full melting in such small droplets results in a steeper $\Delta \mathrm{gv}$, which is easier to detect and, hence, more accurate than in larger droplets, which often melt entirely only with measurable delay; see Fig. 2. The threshold value for automatic detection of the phase transitions was adjusted for each calibration substance, in particular for the solidsolid phase transitions which involve smaller $\Delta \mathrm{gv}$ values. The phase transition temperatures obtained for the reference substances were analyzed by separating the absolute temperature offset of the sample array at a heating rate of 0 (i.e., at static conditions) from its heating rate dependence due to 

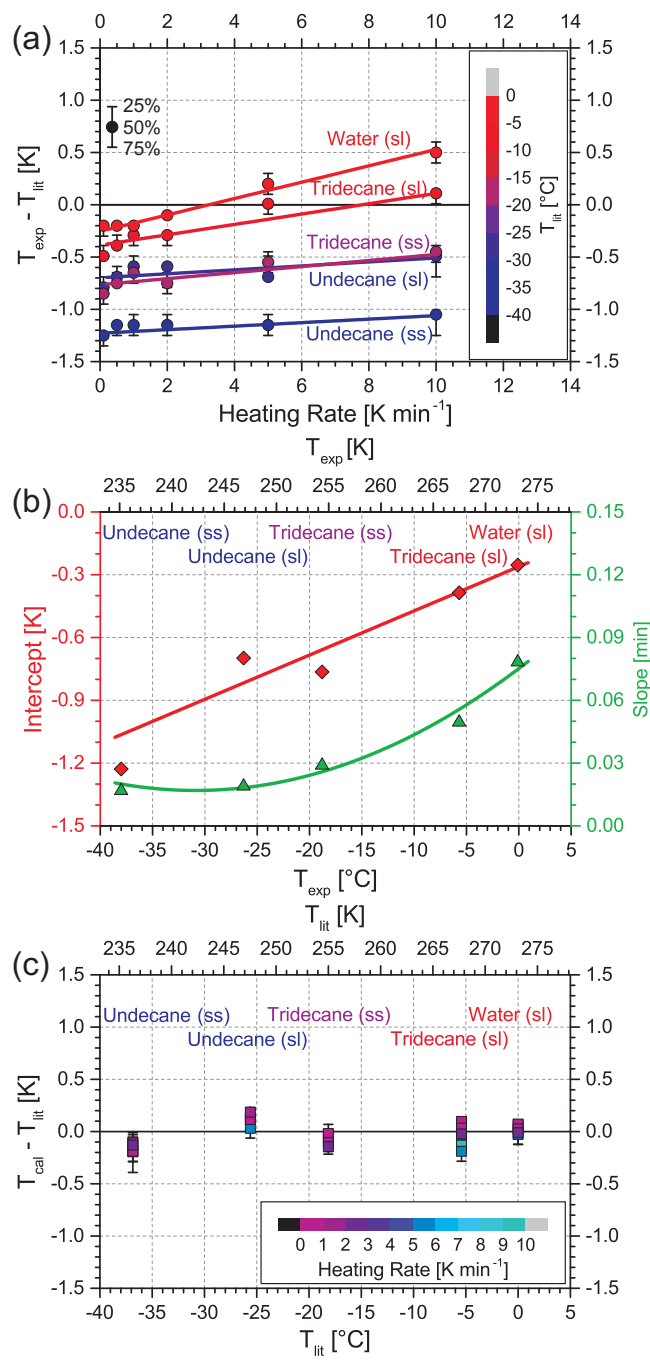

Figure 3. Temperature calibration. (a) Difference between the experimentally determined phase transition temperatures of water, tridecane and undecane droplets and the corresponding literature values as a function of heating rate. Linear fits to the data are indicated by the solid lines. (b) Intercepts (left, red) and slopes (right, green) of the linear fits shown in (a) above. The experimentally determined data (symbols) are fitted by a linear function (intercepts, red line) and by a second-order polynomial (slopes, green line). (c) Residual difference between the calibrated phase transition temperatures and the literature values after calibration.

thermal lag, as recommended for the calibration of thermal devices (Sarge et al., 2000; Della Gatta et al., 2006; Riechers et al., 2013). Figure 3a shows the difference between the experimentally observed temperatures $T_{\exp }$ and the literature values $T_{\mathrm{lit}}$ as a function of heating rate. Points represent the median values, and error bars indicate the 25 th and 75 th percentiles of the data from different compartments and multiple cooling-heating cycles. Each individual reference substance's data set was fitted linearly. The absolute temperature deviation at a heating rate of 0 corresponds to the intercept of such a fit and the heating rate dependence to the slope. The fitting parameters obtained are shown in Fig. $3 \mathrm{~b}$ as a function of $T_{\exp }$ (intercept: red diamonds and left axis; slope: green triangles and right axis). These intercepts are well represented by a linear fit (red line) and the slopes by a second-order polynomial (green line). These fits were then applied to the raw data. The remaining temperature uncertainty after this calibration step, which is the absolute difference between the calibrated temperatures $T_{\mathrm{cal}}$ and the literature values $T_{\mathrm{lit}}$, is shown in Fig. 3c. The squares represent the median values and the error bars the 25th and 75th percentiles for each calibration substance. We note that $\left|T_{\text {cal }}-T_{\text {lit }}\right|$ is smaller than $0.3 \mathrm{~K}$ for $97 \%$ of all individual data points, indicating the quality of the calibration procedure.

\section{Results}

We put the new BINARY setup to the test using Snomax ${ }^{\circledR}$ as a well-studied ice-nucleating substance (Maki et al., 1974; Vali et al., 1976; Ward and DeMott, 1989; Turner et al., 1990; Wood et al., 2002; Möhler et al., 2008; Hartmann et al., 2013; Stopelli et al., 2014). Snomax ${ }^{\circledR}$ is a commercial product containing freeze-dried nonviable bacterial cells from Pseudomonas syringae, which are known to be active INs at high temperature. First, experiments with droplets of $1 \mu \mathrm{L}$ volume were investigated at a cooling rate of $1 \mathrm{~K} \mathrm{~min}^{-1}$. Snomax ${ }^{\circledR}$ concentrations were varied over 6 orders of magnitude between $1 \mathrm{ng} \mathrm{mL}^{-1}$ and $1 \mathrm{mg} \mathrm{mL}^{-1}$, corresponding to a total mass between $1 \mathrm{pg}$ per droplet and $1 \mu \mathrm{g}$ per droplet, respectively. Usually, 108 droplet freezing events (from $3 \times 36$ droplets) were analyzed at each concentration.

The results of these experiments are shown in Fig. 4 by plotting $n_{\mathrm{m}}(T)$, the cumulative number of ice nucleators per $\mu \mathrm{g}$ of Snomax ${ }^{\circledR}$, as a function of temperature. Two particularly strong increases in $n_{\mathrm{m}}(T)$ are observed, one at about $-3.5^{\circ} \mathrm{C}(269.6 \mathrm{~K}) \pm 0.5 \mathrm{~K}$ and one at $-8.5^{\circ} \mathrm{C}(264.6 \mathrm{~K})$ $\pm 0.5 \mathrm{~K}$, indicating the presence of two distinct classes of ice nucleators with different activation temperatures. The two plateaus at temperatures just below each increase of $n_{\mathrm{m}}(T)$ in Fig. 4 arise when no INs active at these temperatures are present in the investigated suspensions. The $n_{\mathrm{m}}(T)$ values of the plateaus differ by about 3 orders of magnitude, from which we infer that the two classes of Snomax ${ }^{\circledR}$ INs occur at a number ratio of about 1 to 1000 in our samples. The active site densities per cell $n_{\mathrm{n}}(T)$ shown in Fig. 4 on the right axis were calculated using the specific particle number of cells in Snomax ${ }^{\circledR}$ determined by Wex et al. (2015); see Sect. 2.1.

It is already known that different types of INs or aggregates of INs are responsible for ice nucleation induced by Pseudomonas and other ice-nucleating bacteria in different temperature ranges (Yankofsky et al., 1981; Turner et al., 1990; Hartmann et al., 2013). For example, Turner et al. (1990) identified three classes of INs on the basis of the temperature at which they triggered ice nucle- 


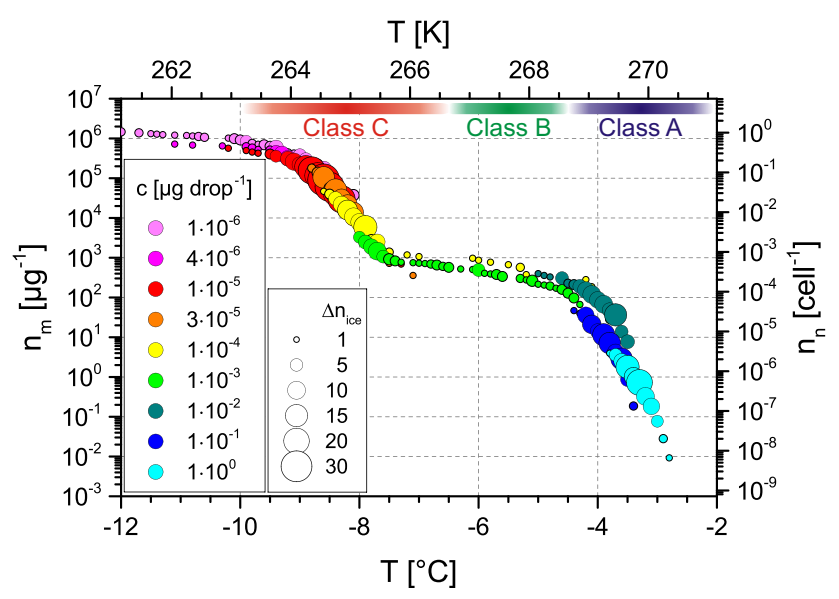

Figure 4. Experimentally determined active site density per unit mass of Snomax ${ }^{\circledR} n_{\mathrm{m}}(T)$ vs. temperature. Symbol colors indicate data from droplets with different Snomax ${ }^{\circledR}$ concentrations; symbol size indicates the number of nucleating droplets per temperature interval. The temperature range for different classes of INs according to the definition by Turner et al. (1990) are also indicated by the colored bars.

ation at various conditions: class $\mathrm{A}$ at high temperature $\left(\gtrsim-4.5^{\circ} \mathrm{C} \simeq 269 \mathrm{~K}\right.$ ), class $\mathrm{B}$ in the intermediate range (approx. -4.5 to $-6.5^{\circ} \mathrm{C} \simeq 269$ to $267 \mathrm{~K}$ ) and class $\mathrm{C}$ at lower temperature $\left(\lesssim-6.5^{\circ} \mathrm{C} \simeq 267 \mathrm{~K}\right)$; see the colored bars at the top of Fig. 4. According to this definition the data shown in Fig. 4 suggest that our sample contained class A and class $\mathrm{C}$ ice-nucleating proteins or protein complexes. In contrast, Turner et al. (1990) identified Snomax ${ }^{\circledR}$ to contain INs of class A and class B, but none of class $\mathrm{C}$. This difference to our study may result from varied growth or storage conditions of different Snomax ${ }^{\circledR}$ samples and is in line with their proposal that class C INs can develop into class B (and subsequently into class A) INs by accumulation of larger icenucleating protein complexes in the cell membranes. In fact, our sample may also contain class B INs, but the low number of freezing events in the corresponding temperature range of -4.5 to $-6.5^{\circ} \mathrm{C}(269$ to $267 \mathrm{~K})$ indicates that there are fewer INs of class B than there are of class A, the latter of which trigger ice nucleation already at higher temperature. As mentioned above, in our sample the more active but less abundant class $\mathrm{A}$ ice nucleators induce freezing at about $-3.5^{\circ} \mathrm{C}$ $(269.6 \mathrm{~K}) \pm 0.5 \mathrm{~K}$, and they dominate the freezing of droplets at a Snomax ${ }^{\circledR}$ concentration of $1 \times 10^{-1} \mu \mathrm{g}$ drop $^{-1}$. The less active but more abundant INs of class $\mathrm{C}$ nucleate ice at about $-8.5^{\circ} \mathrm{C}(264.6 \mathrm{~K}) \pm 0.5 \mathrm{~K}$. At a Snomax ${ }^{\circledR}$ concentration of $1 \times 10^{-5} \mu \mathrm{g}$ drop $^{-1}$ almost all droplets contain such INs of class $\mathrm{C}$, but practically none of class A anymore.

The analysis shown in Fig. 4 is based on the singular approach which assumes that the results are independent of time and, hence, cooling rate. With the new BINARY setup we were able to challenge this assumption by performing experiments at different cooling rates in the range from 0.1 to

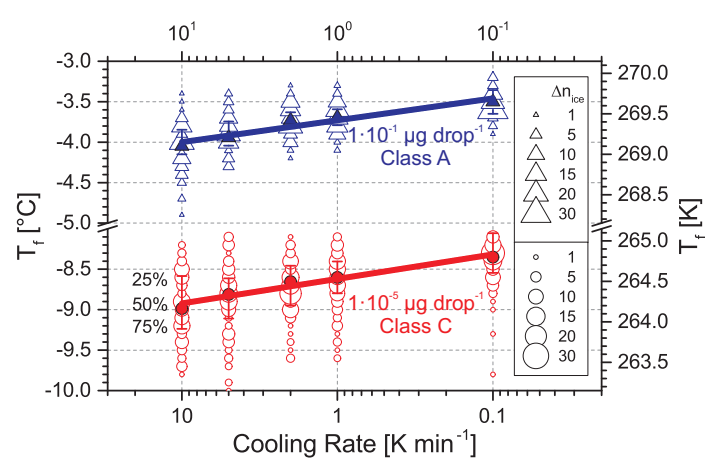

Figure 5. Freezing temperatures of water droplets containing Snomax ${ }^{\circledR}$ at concentrations of $1 \times 10^{-5} \mu \mathrm{gdrop}^{-1}$ (red) and $1 \times 10^{-1} \mu \mathrm{gdrop}^{-1}$ (blue) as a function of experimental cooling rate. The number of nucleation events at individual temperatures is indicated by the size of the open symbols. Solid symbols indicate the median freezing temperature $\left(T_{\mathrm{f}, 50}\right)$, with error bars representing the 25 th and 75 th percentiles. Solid lines are linear fits to the solid symbols; see text.

$10 \mathrm{~K} \mathrm{~min}^{-1}$. In particular the cooling rate dependence of the two IN classes discussed above was investigated. Figure 5 shows a decrease in the median ice nucleation temperature $T_{\mathrm{f}, 50}$ with increasing cooling rate for both classes of INs. The $T_{\mathrm{f}, 50}$ values are represented by filled symbols with error bars indicating the 25th and 75th percentiles. At the indicated concentrations the difference between the $T_{\mathrm{f}, 50}$ values at 10 and at $0.1 \mathrm{~K} \mathrm{~min}^{-1}$ is about $0.6 \mathrm{~K}$ for both classes of INs ( $0.55 \mathrm{~K}$ for class $\mathrm{A}$ and $0.64 \mathrm{~K}$ for class $\mathrm{C})$. These values are small but larger than our temperature uncertainty $( \pm 0.3 \mathrm{~K}$ on a $2 \sigma$ level). While this degree of time dependence is probably not of atmospheric importance, we analyze and quantify it in more detail below for two reasons: first, it is interesting from a physical chemistry viewpoint regarding the fundamental process of heterogeneous ice nucleation; second, such an analysis may help in characterizing the ability and limitations of the BINARY device for measurements of time dependence of INs more generally.

The above analysis suggests a very small time dependence of Snomax ${ }^{\circledR}$-induced ice nucleation. Nevertheless, we may expect to see deviations in the active site density obtained at different cooling rates. Figure 6a shows $n_{\mathrm{m}}(T)$ at the two investigated Snomax ${ }^{\circledR}$ concentrations at different cooling rates. Clearly, there is a systematic trend towards lower $n_{\mathrm{m}}(T)$ with larger cooling rate; i.e., the individual $n_{\mathrm{m}}(T)$ curves are shifted to lower temperature as the cooling rate increases. This analysis supports the interpretation of a time dependence of ice nucleation induced by the two class A and class C Snomax ${ }^{\circledR}$ INs. Therefore, we analyze the data shown in Fig. 6a with the stochastic approach by determining the nucleation rate $R(T)$; see Eq. (6). Figure 6b shows $R(T)$ for both classes of INs. Now the data points obtained from the different cooling rates converge onto a single line, with data obtained at larger cooling rate (yellow) represent- 
ing larger values of $R$ than those obtained at a lower cooling rate (blue). These data of $R(T)$ can be normalized to the total surface area per droplet $A$, using the specific surface area $S^{\prime}=44 \mathrm{~cm}^{2} \mathrm{mg}^{-1}$ of Snomax ${ }^{\circledR}$ from Wex et al. (2015); see Sect. 2.1. For a single-component ice nucleator, $R(T) / A$ is equivalent to nucleation rate coefficient $j_{\text {het }}(T)$; see Eq. (6). The results of the analysis according to Eq. (6) are the data points plotted in Fig. 6c, which shows that $R(T) / A$ increases by about 3 orders of magnitude for a reduction in temperature of about $2 \mathrm{~K}$ for class $\mathrm{C}$ (circles) and by about 4 orders of magnitude for a reduction of about $1 \mathrm{~K}$ for class $\mathrm{A}$ (triangles).

The lines in Fig. 6c are fits to these data using the framework of classical nucleation theory (CNT); i.e., they represent $j_{\text {het }}(T, \alpha)$ fits in which the effective contact angle $\alpha$ was either constant or allowed to have a linear temperature dependence. Figure $6 \mathrm{c}$ shows that the measured data are not well described by CNT when using constant effective contact angle values of $\alpha=23.9^{\circ}$ and $\alpha=35.3^{\circ}$ for class $\mathrm{A}$ and $\mathrm{C}$, respectively (gray lines). Allowing for a linear temperature dependence of $\alpha$, a much better fit of CNT to the data results (red and blue lines). The corresponding linear equations for the temperature-dependent effective contact angles are $\alpha(T)=613.5-2.188 \cdot T$ and $\alpha(T)=286.5-0.9495 \cdot T$ for class $\mathrm{A}$ and $\mathrm{C}$, respectively. (Note that the input temperatures are in units of kelvin.) In order to visualize the effect of the steep increase of $j_{\text {het }}(T)$ with decreasing temperature found for both IN classes, the parameterizations were also used to calculate the nucleation probability $P_{i 0}$ as a function of temperature and observation time (see Fig. A2 in the Appendix).

It is interesting to compare the degree of time dependence of Snomax ${ }^{\circledR}$ with that of INs of atmospheric relevance. For this purpose we follow the approach outlined in Herbert et al. (2014) to quantify the time dependence of Snomax ${ }^{\circledR}$ INs; see Sect. 2.3. Using Eq. (9) on the $T_{\mathrm{f}, 50}$ data shown in Fig. 5 at minimal $\left(0.1 \mathrm{~K} \mathrm{~min}^{-1}\right)$ and maximal $\left(10 \mathrm{~K} \mathrm{~min}^{-1}\right)$ cooling rate yields a value of $\lambda=8.4 \mathrm{~K}^{-1}$ for the class $\mathrm{A}$ INs and $\lambda=$ $7.2 \mathrm{~K}^{-1}$ for class $\mathrm{C}$ INs, respectively (magenta triangles in Fig. 7; see also Table A2 in Appendix A3). Similarly, we can linearly fit the $T_{\mathrm{f}, 50}$ data of Fig. 5 as a function of cooling rate (orange circles in Fig. 7). We note that those two different ways for deriving $\lambda$ agree well with each other; see Fig. 7 and Table A2. Moreover, we can also determine the parameter $\omega$ from fitting a straight line to $\ln (R(T) / A)$ vs. $T$ data of Fig. 6c, resulting in the green diamonds in Fig. 7.

The nonlinear behavior of the $R(T) / A$ data in the logarithmic plot of Fig. $6 \mathrm{c}$ suggests that $\lambda$ is not constant but instead shows a temperature dependence itself. For these reasons we finally derive $\lambda(T)$ by taking the derivative of the CNT fit resulting in the red and blue lines for $\lambda(T)$ over the investigated temperature range (Fig. 7). Clearly, the $\omega$ value is consistent with the $\lambda(T)$ value in that it represents an average value over the investigated temperature range. However, the strong difference between $\omega$ and $\lambda$ obtained for the

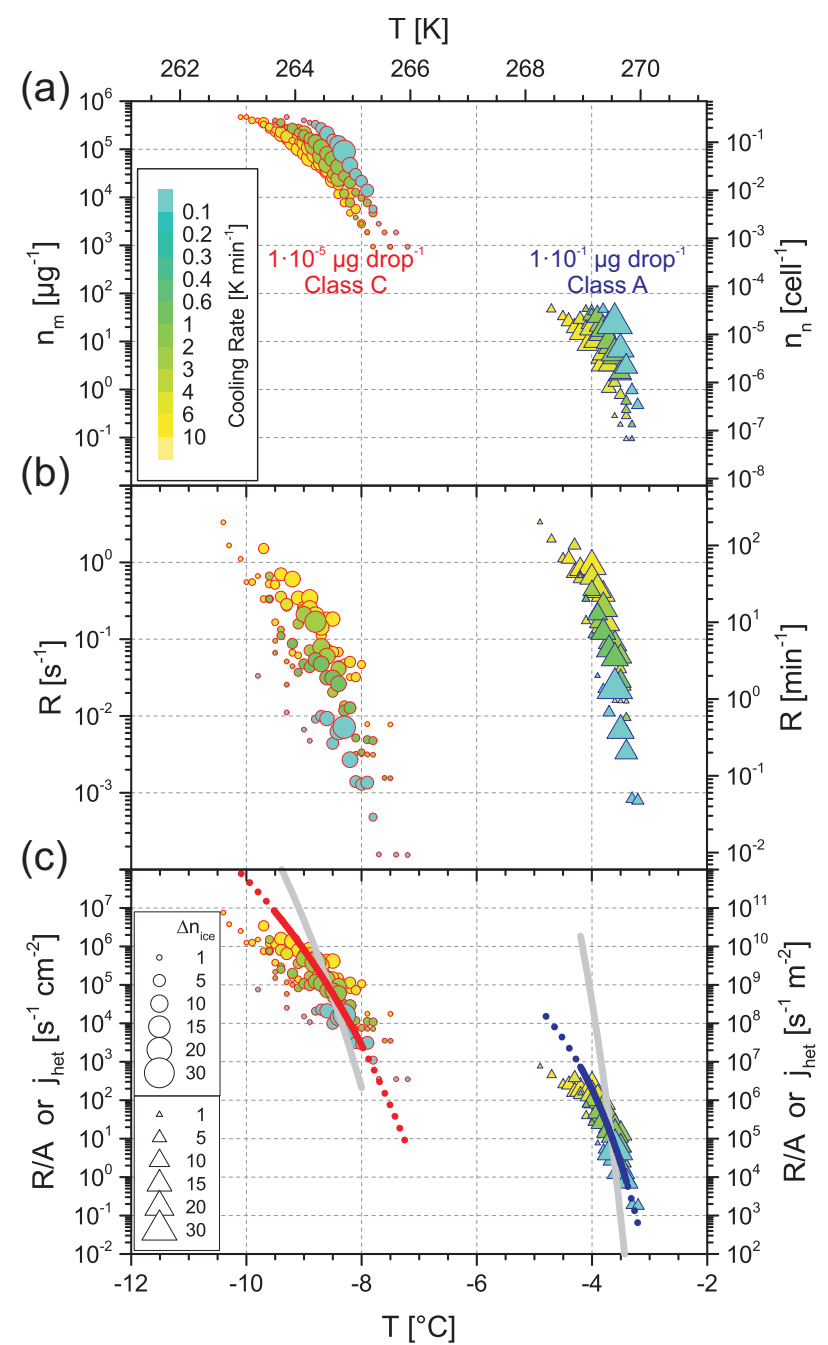

Figure 6. (a) Cooling rate dependence of the active site densities per mass $\left(n_{\mathrm{m}}(T)\right)$ and per cell $\left(n_{\mathrm{n}}(T)\right)$ vs. temperature for two classes of INs determined from droplets containing the indicated Snomax ${ }^{\circledR}$ concentrations. (b) Stochastic analysis of the data from (a) in terms of the nucleation rate $R(T)$. (c) Normalized nucleation rate $R(T) / A$ data derived from the $R(T)$ data in (b) following Eq. (6) (data points) and analysis of these data in terms of the heterogeneous ice nucleation rate coefficient $j_{\text {het }}(T)$ using CNT with a constant effective contact angle $\alpha$ (gray lines) and a linear temperature dependence of $\alpha$ (colored lines).

class C INs and the fact that $\omega<\lambda$ indicate that class C INs may consist of a multi-component set of INs (see discussion in Herbert et al., 2014). In contrast, the good agreement between $\omega$ and $\lambda$ obtained for the class A INs suggests that these are indeed single-component INs; hence, $\omega=\lambda$ in this case. We recommend a numerical value of $\omega=\lambda=8.7 \mathrm{~K}^{-1}$ for class A Snomax ${ }^{\circledR}$ INs at the median freezing temperature of $-3.8^{\circ} \mathrm{C}(269.4 \mathrm{~K})$.

The $\lambda$ values derived here can be compared to values for other types of INs from the literature. For example, the values for various mineral dusts (Arizona Test Dust (ATD), il- 


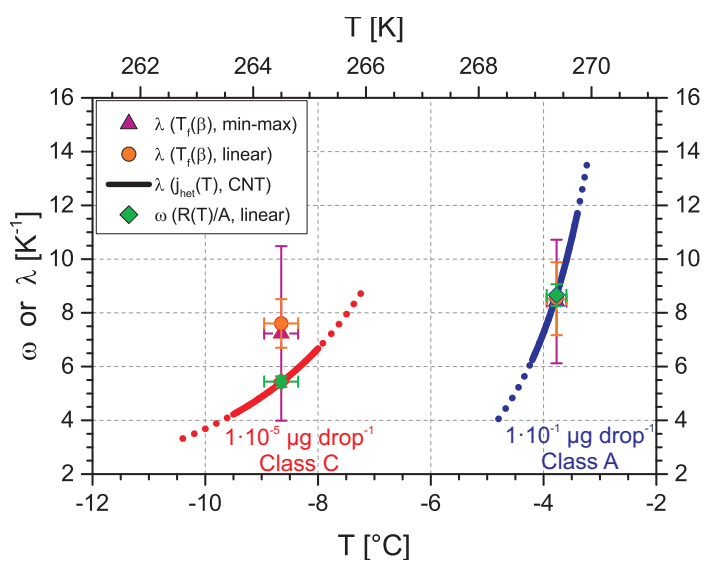

Figure 7. Value of $\omega$ and $\lambda$ derived in different ways for the two indicated classes of Snomax ${ }^{\circledR}$ INs. Magenta triangle: $\lambda$ obtained from Eq. (9) at the minimal $\left(0.1 \mathrm{Kmin}^{-1}\right)$ and maximal $\left(10 \mathrm{~K} \mathrm{~min}^{-1}\right)$ cooling rate. Orange circle: $\lambda$ obtained from the linear fits to the $T_{\mathrm{f}, 50}$ data shown in Fig. 5. Green diamond: $\omega=-\mathrm{d} \ln (R / A) / \mathrm{d} T$ obtained from a linear fit to the $R(T) / A$ data shown in Fig. 6c. Lines indicate $\lambda$ derived from the derivative of the nucleation rate coefficient $-\mathrm{d} \ln \left(j_{\text {het }}\right) / \mathrm{d} T$ based on CNT with a temperature-dependent contact angle; for details see text.

lite NX, kaolinite KGa-1b and feldspar) range between about 1 and $4.6 \mathrm{~K}^{-1}$ (Murray et al., 2011; Wright and Petters, 2013; Hiranuma et al., 2013; Knopf and Alpert, 2013; Vali, 2014; Herbert et al., 2014). Furthermore, the literature analysis of $\lambda$ values by Herbert et al. (2014) includes also other types of INs. This comparison indicates the smallest value of $\lambda=0.6 \mathrm{~K}^{-1}$ for volcanic ash (Fornea et al., 2009; Hoyle et al., 2011; Steinke et al., 2011), and the highest value of $\lambda=6.3 \mathrm{~K}^{-1}$ for a soil sample (Vali, 2008). The small $\lambda$ values for most IN compounds emphasize the stochastic nature of heterogenous ice nucleation in these cases, as small $\lambda$ values correspond to a large time dependence, and vice versa. These values can be compared to homogeneous ice nucleation data in pure water at temperatures between about $-38^{\circ} \mathrm{C}(235 \mathrm{~K})$ and $-35^{\circ} \mathrm{C}(238 \mathrm{~K})$, which show a mean value of $\lambda=3.4 \pm 1.2 \mathrm{~K}^{-1}$ (Riechers et al., 2013).

A comparison of these literature values with those obtained here for Snomax ${ }^{\circledR}$ shows a larger $\lambda$ value and implies a very small "stochasticity" of the responsible Snomax ${ }^{\circledR}$ IN moieties. To our knowledge the value of $\lambda=8.7 \mathrm{~K}^{-1}$ for the class A INs of Snomax ${ }^{\circledR}$ obtained here is the largest $\lambda$ value reported to date, indicating that the time dependence of Snomax ${ }^{\circledR}$ is particularly small when compared to INs of atmospheric relevance.

\section{Conclusions}

Herein we introduced the novel optical freezing array BINARY for studying the temperature and time dependence of heterogeneous ice nucleation in the immersion mode. The principal advantages of the technique is prevention of a Wegener-Bergeron-Findeisen type water vapor transfer between unfrozen and frozen droplets and of a seeding of neighboring droplets by formation and surface growth of frost halos. The simultaneous study of 36 droplets and a fully automated evaluation of the ice nucleation temperature in each droplet from a real-time image analysis allows for a facile and fast accumulation of data points. Moreover, the microliter volume of the investigated droplets permits a preparation of droplets with IN concentrations varying over several orders of magnitude, thus enabling the detection of rare ice nucleators of high activity. The BINARY setup was tested by studying heterogeneous ice nucleation induced by Snomax ${ }^{\circledR}$ suspended in water droplets at various concentrations from $1 \mathrm{ng} \mathrm{mL}^{-1}$ to $1 \mathrm{mg} \mathrm{mL}^{-1}$. Two types of INs were identified, namely class $\mathrm{A}$ and class $\mathrm{C}$ ice nucleators. Using different cooling rates, we were able to show that these INs exhibit a very small time dependence, which we quantified by analyzing the experimental data in terms of the temperature dependence $\lambda$ of the ice nucleation rate coefficient. While class C Snomax ${ }^{\circledR}$ INs appear to be multicomponent, the data for class A are consistent with the behavior of a single-component IN. To the best of our knowledge, the resulting $\lambda=8.7 \mathrm{~K}^{-1}$ for the class A Snomax ${ }^{\circledR} \mathrm{INs}$ is the largest $\lambda$ value reported to date, equivalent to a particularly small time dependence. Moreover, the fact that we could quantify such a small time dependence suggests that the BINARY setup introduced here is suitable for measuring time dependence for most other INs of atmospheric interest, making it a useful tool for future analysis. 


\section{Appendix A: Additional information and data analysis}

\section{A1 Calibration literature values}

For the temperature calibration described in Sect. 4 information about the literature values of the phase transitions of the reference substances were required. Most of the values are taken from Linstrom and Mallard (2014) and publications cited therein. Data which were excluded from the overall average by the National Institute of Standards and Technology (NIST) were also excluded here. In addition to the NIST data, values were taken from Parks and Huffman (1931), Messerly et al. (1967) and Mondieig et al. (2004). Figure A1 shows an overview of all data used here. A summary of the particular phase transitions and the median literature values are given in Table A1.

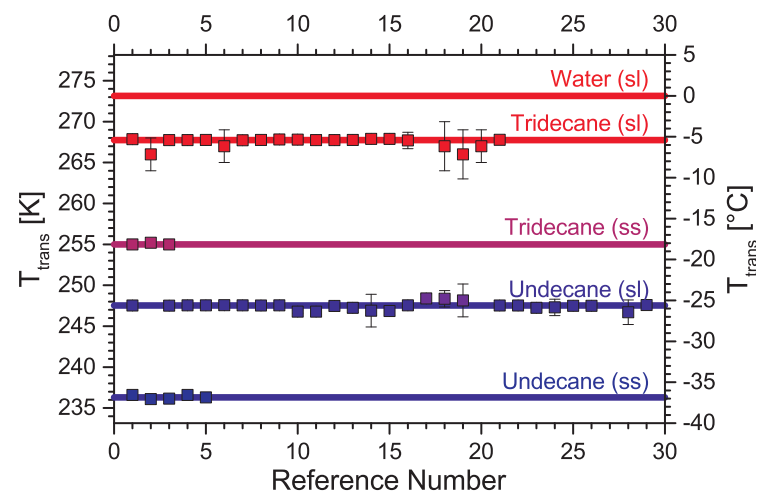

Figure A1. Literature values for the phase transitions of water, tridecane and undecane used for the temperature calibration. Symbols indicate individual literature values, and the lines represent their median used for the calibration. For data see Table A1.

Table A1. Substances and their median phase transition temperatures derived from several sources which were used in the calibration of the BINARY setup. The errors indicate the 25th and 75th percentiles.

\begin{tabular}{ccccr}
\hline Substance & Purity & $\begin{array}{c}\text { Type of } \\
\text { transition }\end{array}$ & $\begin{array}{c}\text { Number of } \\
\text { data points }\end{array}$ & $\begin{array}{r}T_{\text {lit, } 50 \%} \\
{\left[{ }^{\circ} \mathrm{C}\right]}\end{array}$ \\
\hline Water & double-distilled & solid-liquid & - & $0.00_{-0.39}^{+0.05}$ \\
Tridecane & $\geq 99.5 \%$ & solid-liquid & 20 & $-5.41_{-0.39}^{+0.05}$ \\
Tridecane & $\geq 99.5 \%$ & solid-solid & 3 & $-18.15_{-0.00}^{+0.20}$ \\
Undecane & $\geq 99.8 \%$ & solid-liquid & 26 & $-25.61_{-0.29}^{+0.01}$ \\
Undecane & $\geq 99.8 \%$ & solid-solid & 5 & $-36.85_{-0.15}^{+0.30}$ \\
\hline
\end{tabular}

\section{A2 Ice nucleation probability}

The CNT parameterizations with a temperature-dependent $\alpha(T)$ shown as red and blue lines in Fig. 6c were used to calculate the ice nucleation probability $P_{i 0}$ as a function of time and temperature for typical experimental conditions. Here

$P_{i 0}(T, \Delta t)=\frac{\Delta n_{\text {ice }}(T, \Delta t)}{n_{\text {liq }}\left(T, t_{1}\right)}=1-e^{-R(T) \Delta t}$

represents the number of frozen droplets $\Delta n_{\text {ice }}(T, \Delta t)=$ $n_{\text {liq }}\left(T, t_{1}\right)-n_{\text {liq }}\left(T, t_{2}\right)$ at constant temperature $T$ in a time interval $\Delta t=t_{2}-t_{1}$. Figure A2 shows the results for 1 microliter droplets containing $\operatorname{Snomax}^{\circledR}$ at $1 \times 10^{-1} \mu \mathrm{gdrop}^{-1}$ (class A) in the top panel a and for droplets containing Snomax ${ }^{\circledR}$ at $1 \times 10^{-5} \mu \mathrm{g}$ drop $^{-1}$ (class C) in the bottom panel b. The contour plots indicate very abrupt changes of the nucleation probabilities from 0 to 1 with decreasing temperature for both classes of INs. The corresponding temperature interval in which the transition occurs is smaller than about $0.5 \mathrm{~K}$ for time intervals of $0.1 \mathrm{~s}$ for class C INs. An even-smaller temperature interval of about $0.2 \mathrm{~K}$ results for larger time intervals and class A INs at $1 \times 10^{-1} \mu \mathrm{g} \mathrm{drop}^{-1}$. Figure A2 reinforces our interpretation provided in the Results section that the ice nucleation probability of Snomax ${ }^{\circledR}$ INs also shows a very strong temperature dependence but only a small time dependence.

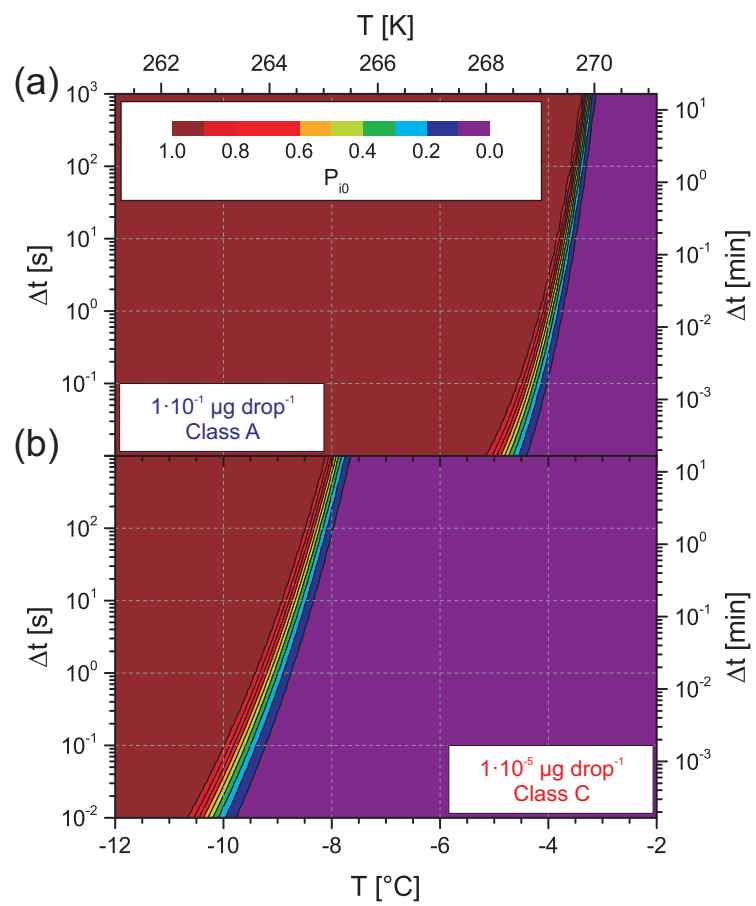

Figure A2. Contour plot of the nucleation probabilities $P_{i 0}$ as a function of time and temperature for the parametrization using CNT and temperature-dependent contact angles shown in Fig. 6c for the two investigated concentrations of $1 \times 10^{-1} \mu \mathrm{gdrop}{ }^{-1}$ (a) and $1 \times 10^{-5} \mu \mathrm{g} \operatorname{drop}^{-1}$ (b). 


\section{A3 Values for time dependence of Snomax ${ }^{\circledR}$ INs}

In Table A2 we provide the results of the quantification of time dependence according to Sect. 2.3 and described in Sect. 5. The values of this analysis for two IN classes shown in Fig. 7 are provided in the following table.

Table A2. Values of $\lambda$ and $\omega$ determined using different approaches for the two investigated IN classes at their median freezing temperature (given in brackets); for details see text. These data are shown also in Fig. 7.

\begin{tabular}{clll}
\hline Parameter & Method & $\begin{array}{l}\text { Class C } \\
\left(-8.6 \pm 0.3^{\circ} \mathrm{C}\right)\end{array}$ & $\begin{array}{l}\text { Class A } \\
\left(-3.8 \pm 0.2^{\circ} \mathrm{C}\right)\end{array}$ \\
\hline$\lambda$ & $T_{\mathrm{f}}(\beta)$, min-max & $7.2 \pm 3.2 \mathrm{~K}^{-1}$ & $8.4 \pm 2.3 \mathrm{~K}^{-1}$ \\
$\lambda$ & $T_{\mathrm{f}}(\beta)$, linear & $7.6 \pm 0.9 \mathrm{~K}^{-1}$ & $8.5 \pm 1.4 \mathrm{~K}^{-1}$ \\
$\omega$ & $R(T) / A$, linear & $5.4 \pm 0.2 \mathrm{~K}^{-1}$ & $8.7 \pm 0.4 \mathrm{~K}^{-1}$ \\
\hline
\end{tabular}




\section{The Supplement related to this article is available online at doi:10.5194/amt-8-689-2015-supplement.}

Acknowledgements. The authors gratefully acknowledge funding by the German Research Foundation (DFG) through the research unit INUIT (FOR 1525) under KO 2944/2-1. We particularly thank our INUIT partners for fruitful collaboration and sharing of ideas and IN samples. We also thank K. Dreischmeier and D. Cherian for testing and discussing features of the BINARY setup, and R. Herbert and B. Murray for helpful discussions on $\lambda$ analysis.

Edited by: B. Ervens

\section{References}

Atkinson, J. D., Murray, B. J., Woodhouse, M. T., Whale, T. F., Baustian, K. J., Carslaw, K. S., Dobbie, S., O'Sullivan, D., and Malkin, T. L.: The importance of feldspar for ice nucleation by mineral dust in mixed-phase clouds, Nature, 498, 355-358, doi:10.1038/nature12278, 2013.

Attard, E., Yang, H., Delort, A.-M., Amato, P., Pöschl, U., Glaux, C., Koop, T., and Morris, C. E.: Effects of atmospheric conditions on ice nucleation activity of Pseudomonas, Atmos. Chem. Phys., 12, 10667-10677, doi:10.5194/acp-1210667-2012, 2012.

Barahona, D.: On the ice nucleation spectrum, Atmos. Chem. Phys., 12, 3733-3752, doi:10.5194/acp-12-3733-2012, 2012.

Barlow, T. W. and Haymet, A. D. J.: ALTA: An automated lag-time apparatus for studying the nucleation of supercooled liquids, Rev. Sci. Instrum., 66, 2996, doi:10.1063/1.1145586, 1995.

Bigg, E. K.: The supercooling of water, Proc. Phys. Soc. Sect. B, 66, 688-694, doi:10.1088/0370-1301/66/8/309, 1953.

Cantrell, W. and Heymsfield, A.: Production of Ice in Tropospheric Clouds: A Review, B. Am. Meteorol. Soc., 86, 795-807, doi:10.1175/BAMS-86-6-795, 2005.

Connolly, P. J., Möhler, O., Field, P. R., Saathoff, H., Burgess, R., Choularton, T., and Gallagher, M.: Studies of heterogeneous freezing by three different desert dust samples, Atmos. Chem. Phys., 9, 2805-2824, doi:10.5194/acp-9-2805-2009, 2009.

Cziczo, D. J. and Froyd, K. D.: Sampling the composition of cirrus ice residuals, Atmos. Res., 142, 15-31, doi:10.1016/j.atmosres.2013.06.012, 2014.

Della Gatta, G., Richardson, M. J., Sarge, S. M., and Stølen, S.: Standards, calibration, and guidelines in microcalorimetry. Part 2. Calibration standards for differential scanning calorimetry (IUPAC Technical Report), Pure Appl. Chem., 78, 1455-1476, doi:10.1351/pac200678071455, 2006.

DeMott, P. J., Prenni, A. J., Liu, X., Kreidenweis, S. M., Petters, M. D., Twohy, C. H., Richardson, M. S., Eidhammer, T., and Rogers, D. C.: Predicting global atmospheric ice nuclei distributions and their impacts on climate, P. Natl. Acad. Sci. USA, 107, 11217-11222, doi:10.1073/pnas.0910818107, 2010.

Ervens, B. and Feingold, G.: On the representation of immersion and condensation freezing in cloud models using different nucleation schemes, Atmos. Chem. Phys., 12, 5807-5826, doi:10.5194/acp-12-5807-2012, 2012.
Ervens, B. and Feingold, G.: Sensitivities of immersion freezing: reconciling classical nucleation theory and deterministic expressions, Geophys. Res. Lett., 40, 3320-3324, doi:10.1002/grl.50580, 2013.

Fletcher, N. H.: Active sites and ice crystal nucleation, J. Atmos. Sci., 26, 1266-1271, doi:10.1175/15200469(1969)026<1266:ASAICN>2.0.CO;2, 1969.

Fornea, A. P., Brooks, S. D., Dooley, J. B., and Saha, A.: Heterogeneous freezing of ice on atmospheric aerosols containing ash, soot, and soil, J. Geophys. Res., 114, D13201, doi:10.1029/2009JD011958, 2009.

Hartmann, S., Augustin, S., Clauss, T., Wex, H., Šantl-Temkiv, T., Voigtländer, J., Niedermeier, D., and Stratmann, F.: Immersion freezing of ice nucleation active protein complexes, Atmos. Chem. Phys., 13, 5751-5766, doi:10.5194/acp-13-57512013, 2013.

Heneghan, A. F., Wilson, P. W., and Haymet, A. D. J.: Heterogeneous nucleation of supercooled water, and the effect of an added catalyst, P. Natl. Acad. Sci. USA, 99, 9631-9634, doi:10.1073/pnas.152253399, 2002.

Herbert, R. J., Murray, B. J., Whale, T. F., Dobbie, S. J., and Atkinson, J. D.: Representing time-dependent freezing behaviour in immersion mode ice nucleation, Atmos. Chem. Phys., 14, 85018520, doi:10.5194/acp-14-8501-2014, 2014.

Hiranuma, N., Möhler, O., Bingemer, H., Bundke, U., Cziczo, D. J., Danielczok, A., Ebert, M., Garimella, S., Hoffmann, N., Höhler, K., Kanji, Z. A., Kiselev, A., Raddatz, M., and Stetzer, O.: Immersion freezing of clay minerals and bacterial ice nuclei, in: Nucleation Atmos. Aerosols (AIP Conf. Proc. 1527), edited by: DeMott, P. J. and O'Dowd, C. D., 914-917, doi:10.1063/1.4803420, AIP Publishing, Melville, NY, USA, 2013.

Hoffer, T. E.: A laboratory investigation of droplet freezing, J. Meteorol., 18, 766-778, doi:10.1175/15200469(1961)018<0766:ALIODF>2.0.CO;2, 1961.

Hoose, C. and Möhler, O.: Heterogeneous ice nucleation on atmospheric aerosols: a review of results from laboratory experiments, Atmos. Chem. Phys., 12, 9817-9854, doi:10.5194/acp-12-98172012, 2012.

Hoyle, C. R., Pinti, V., Welti, A., Zobrist, B., Marcolli, C., Luo, B., Höskuldsson, Á., Mattsson, H. B., Stetzer, O., Thorsteinsson, T., Larsen, G., and Peter, T.: Ice nucleation properties of volcanic ash from Eyjafjallajökull, Atmos. Chem. Phys., 11, 9911-9926, doi:10.5194/acp-11-9911-2011, 2011.

Iannone, R., Chernoff, D. I., Pringle, A., Martin, S. T., and Bertram, A. K.: The ice nucleation ability of one of the most abundant types of fungal spores found in the atmosphere, Atmos. Chem. Phys., 11, 1191-1201, doi:10.5194/acp-11-1191-2011, 2011.

Jung, S., Tiwari, M. K., and Poulikakos, D.: Frost halos from supercooled water droplets, P. Natl. Acad. Sci. USA, 109, 1607316078, doi:10.1073/pnas.1206121109, 2012.

Knopf, D. A. and Lopez, M. D.: Homogeneous ice freezing temperatures and ice nucleation rates of aqueous ammonium sulfate and aqueous levoglucosan particles for relevant atmospheric conditions, Phys. Chem. Chem. Phys., 11, 8056-8068, doi:10.1039/b903750k, 2009.

Knopf, D. A. and Alpert, P. A.: A water activity based model of heterogeneous ice nucleation kinetics for freezing of water 
and aqueous solution droplets, Faraday Discuss., 165, 513-534, doi:10.1039/c3fd00035d, 2013.

Koop, T. and Zobrist, B.: Parameterizations for ice nucleation in biological and atmospheric systems, Phys. Chem. Chem. Phys., 11, 10839-10850, doi:10.1039/b914289d, 2009.

Koop, T., Luo, B., Biermann, U. M., Crutzen, P. J., and Peter, T.: Freezing of $\mathrm{HNO}_{3} / \mathrm{H}_{2} \mathrm{SO}_{4} / \mathrm{H}_{2} \mathrm{O}$ solutions at stratospheric temperatures: nucleation statistics and experiments, J. Phys. Chem. A, 101, 1117-1133, doi:10.1021/jp9626531, 1997.

Koop, T., Ng, H. P., Molina, L. T., and Molina, M. J.: A new optical technique to study aerosol phase transitions: the nucleation of ice from $\mathrm{H}_{2} \mathrm{SO}_{4}$ aerosols, J. Phys. Chem. A, 102, 8924-8931, doi:10.1021/jp9828078, 1998.

Koop, T., Luo, B., Tsias, A., and Peter, T.: Water activity as the determinant for homogeneous ice nucleation in aqueous solutions, Nature, 406, 611-614, doi:10.1038/35020537, 2000.

Kulkarni, G., Fan, J., Comstock, J. M., Liu, X., and Ovchinnikov, M.: Laboratory measurements and model sensitivity studies of dust deposition ice nucleation, Atmos. Chem. Phys., 12, 72957308, doi:10.5194/acp-12-7295-2012, 2012.

Lamb, D. and Verlinde, J.: Physics and Chemistry of Clouds, Cambridge University Press, Cambridge, doi:10.1017/CBO9780511976377, 2011.

Linstrom, P. J. and Mallard, W. G. (Eds.): NIST Chemistry WebBook, NIST Standard Reference Database Number 69, National Institute of Standards and Technology, Gaithersburg MD, 20899, available at: http://webbook.nist.gov, last access: 8 September 2014.

Lohmann, U. and Diehl, K.: Sensitivity studies of the importance of dust ice nuclei for the indirect aerosol effect on stratiform mixed-phase clouds, J. Atmos. Sci., 63, 968-982, doi:10.1175/JAS3662.1, 2006.

Lüönd, F., Stetzer, O., Welti, A., and Lohmann, U.: Experimental study on the ice nucleation ability of size-selected kaolinite particles in the immersion mode, J. Geophys. Res., 115, D14201, doi:10.1029/2009JD012959, 2010.

Maki, L. R., Galyan, E. L., Chang-Chien, M. M., and Caldwell, D. R.: Ice nucleation induced by pseudomonas syringae, Appl. Microbiol., 28, 456-459, 1974.

Messerly, J. F., Guthrie, G. B., Todd, S. S., and Finke, H. L.: Low-temperature thermal data for pentane, n-heptadecane, and n-octadecane. Revised thermodynamic functions for the n-alkanes, C5-C18, J. Chem. Eng. Data, 12, 338-346, doi:10.1021/je60034a014, 1967.

Möhler, O., Georgakopoulos, D. G., Morris, C. E., Benz, S., Ebert, V., Hunsmann, S., Saathoff, H., Schnaiter, M., and Wagner, R.: Heterogeneous ice nucleation activity of bacteria: new laboratory experiments at simulated cloud conditions, Biogeosciences, 5, 1425-1435, doi:10.5194/bg-5-1425-2008, 2008.

Mondieig, D., Rajabalee, F., Metivaud, V., Oonk, H. A. J., and Cuevas-Diarte, M. A.: n-alkane binary molecular alloys, Chem. Mater., 16, 786-798, doi:10.1021/cm031169p, 2004.

Murphy, D. M. and Koop, T.: Review of the vapour pressures of ice and supercooled water for atmospheric applications, Q. J. Roy. Meteorol. Soc., 131, 1539-1565, doi:10.1256/qj.04.94, 2005.

Murray, B. J., Broadley, S. L., Wilson, T. W., Bull, S. J., Wills, R. H., Christenson, H. K., and Murray, E. J.: Kinetics of the homogeneous freezing of water, Phys. Chem. Chem. Phys., 12, 1038010387, doi:10.1039/c003297b, 2010.
Murray, B. J., Broadley, S. L., Wilson, T. W., Atkinson, J. D., and Wills, R. H.: Heterogeneous freezing of water droplets containing kaolinite particles, Atmos. Chem. Phys., 11, 4191-4207, doi:10.5194/acp-11-4191-2011, 2011.

Murray, B. J., O'Sullivan, D., Atkinson, J. D., and Webb, M. E.: Ice nucleation by particles immersed in supercooled cloud droplets, Chem. Soc. Rev., 41, 6519-6554, doi:10.1039/c2cs35200a, 2012.

Niedermeier, D., Hartmann, S., Shaw, R. A., Covert, D., Mentel, T. F., Schneider, J., Poulain, L., Reitz, P., Spindler, C., Clauss, T., Kiselev, A., Hallbauer, E., Wex, H., Mildenberger, K., and Stratmann, F.: Heterogeneous freezing of droplets with immersed mineral dust particles - measurements and parameterization, Atmos. Chem. Phys., 10, 3601-3614, doi:10.5194/acp-103601-2010, 2010.

Niemand, M., Möhler, O., Vogel, B., Vogel, H., Hoose, C., Connolly, P., Klein, H., Bingemer, H., DeMott, P., Skrotzki, J., and Leisner, T.: A particle-surface-area-based parameterization of immersion freezing on desert dust particles, J. Atmos. Sci., 69, 3077-3092, doi:10.1175/JAS-D-11-0249.1, 2012.

O'Sullivan, D., Murray, B. J., Malkin, T. L., Whale, T. F., Umo, N. S., Atkinson, J. D., Price, H. C., Baustian, K. J., Browse, J., and Webb, M. E.: Ice nucleation by fertile soil dusts: relative importance of mineral and biogenic components, Atmos. Chem. Phys., 14, 1853-1867, doi:10.5194/acp-14-18532014, 2014.

Parks, G. S. and Huffman, H. M.: Some fusion and transition data for hydrocarbons, Ind. Eng. Chem., 23, 1138-1139, doi:10.1021/ie50262a018, 1931.

Pruppacher, H. R. and Klett, J. D.: Microphysics of Clouds and Precipitation, 2nd Edn., Kluwer Academic Publishers, New York, 1997.

Pummer, B. G., Bauer, H., Bernardi, J., Bleicher, S., and Grothe, H.: Suspendable macromolecules are responsible for ice nucleation activity of birch and conifer pollen, Atmos. Chem. Phys., 12, 2541-2550, doi:10.5194/acp-12-2541-2012, 2012.

Remmers, M. L.: Kerzenruß als Vorläufer für robuste und transparente superamphiphobe Beschichtungen, Ba thesis, Bielefeld University, Bielefeld, 2012.

Riechers, B., Wittbracht, F., Hütten, A., and Koop, T.: The homogeneous ice nucleation rate of water droplets produced in a microfluidic device and the role of temperature uncertainty, Phys. Chem. Chem. Phys., 15, 5873-5887, doi:10.1039/c3cp42437e, 2013.

Salcedo, D., Molina, L. T., and Molina, M. J.: Nucleation rates of nitric acid dihydrate in $1: 2 \mathrm{HNO}_{3} / \mathrm{H}_{2} \mathrm{O}$ solutions at stratospheric temperatures, Geophys. Res. Lett., 27, 193, doi:10.1029/1999GL010991, 2000.

Sarge, S. M., Höhne, G. W., Cammenga, H. K., Eysel, W., and Gmelin, E.: Temperature, heat and heat flow rate calibration of scanning calorimeters in the cooling mode, Thermochim. Acta, 361, 1-20, doi:10.1016/S0040-6031(00)00543-8, 2000.

Steinke, I., Möhler, O., Kiselev, A., Niemand, M., Saathoff, H., Schnaiter, M., Skrotzki, J., Hoose, C., and Leisner, T.: Ice nucleation properties of fine ash particles from the Eyjafjallajökull eruption in April 2010, Atmos. Chem. Phys., 11, 12945-12958, doi:10.5194/acp-11-12945-2011, 2011.

Stopelli, E., Conen, F., Zimmermann, L., Alewell, C., and Morris, C. E.: Freezing nucleation apparatus puts new slant on study of 
biological ice nucleators in precipitation, Atmos. Meas. Tech., 7, 129-134, doi:10.5194/amt-7-129-2014, 2014.

Turner, M. A., Arellano, F., and Kozloff, L. M.: Three separate classes of bacterial ice nucleation structures, J. Bacteriol., 172, 2521-2526, 1990.

Vali, G.: Supercooling of water and nucleation of ice (drop freezer), Am. J. Phys., 39, 1125-1128, doi:10.1119/1.1976585, 1971a.

Vali, G.: Quantitative Evaluation of Experimental Results an the Heterogeneous Freezing Nucleation of Supercooled Liquids, J. Atmos. Sci., 28, 402-409, doi:10.1175/15200469(1971)028<0402:QEOERA>2.0.CO;2, 1971 b.

Vali, G.: Freezing rate due to heterogeneous nucleation, J. Atmos. Sci., 51, 1843-1856, doi:10.1175/15200469(1994)051<1843:FRDTHN>2.0.CO;2, 1994.

Vali, G.: Repeatability and randomness in heterogeneous freezing nucleation, Atmos. Chem. Phys., 8, 5017-5031, doi:10.5194/acp-8-5017-2008, 2008.

Vali, G.: Interpretation of freezing nucleation experiments: singular and stochastic; sites and surfaces, Atmos. Chem. Phys., 14, 5271-5294, doi:10.5194/acp-14-5271-2014, 2014.

Vali, G. and Stansbury, E. J.: Time-dependet characteristics of the heterogeneous nucleation of ice, Can. J. Phys., 44, 477-502, doi:10.1139/p66-044, 1966.

Vali, G. and Snider, J. R.: Time-dependent freezing rate parcel model, Atmos. Chem. Phys. Discuss., 14, 29305-29329, doi:10.5194/acpd-14-29305-2014, 2014.

Vali, G., Christensen, M., Fresh, R. W., Galyan, E. L., Maki, L. R., and Schnell, R. C.: Biogenic Ice Nuclei. Part II: Bacterial Sources, J. Atmos. Sci., 33, 1565-1570, doi:10.1175/15200469(1976)033<1565:BINPIB>2.0.CO;2, 1976.

Vonnegut, B. and Baldwin, M.: Repeated nucleation of a supercooled water sample that contains silver iodide particles, J. Clim. Appl. Meteorol., 23, 486-490, doi:10.1175/15200450(1984)023<0486:RNOASW>2.0.CO;2, 1984.
Ward, P. J. and DeMott, P. J.: Preliminary experimental evaluation of Snomax Snow Inducer, Pseudomonas syringae, as an artificial ice nucleus for weather modification, J. Weather Modif., 21, 9$13,1989$.

Welti, A., Lüönd, F., Kanji, Z. A., Stetzer, O., and Lohmann, U.: Time dependence of immersion freezing: an experimental study on size selected kaolinite particles, Atmos. Chem. Phys., 12, 9893-9907, doi:10.5194/acp-12-9893-2012, 2012.

Welz, T.: Untersuchung der Eisnukleation in wässrigen Birkenpollensuspensionen, Ba thesis, Bielefeld University, Bielefeld, 2013.

Wex, H., Augustin-Bauditz, S., Boose, Y., Budke, C., Curtius, J., Diehl, K., Dreyer, A., Frank, F., Hartmann, S., Hiranuma, N., Jantsch, E., Kanji, Z. A., Kiselev, A., Koop, T., Möhler, O., Niedermeier, D., Nillius, B., Rösch, M., Rose, D., Schmidt, C., Steinke, I., and Stratmann, F.: Intercomparing different devices for the investigation of ice nucleating particles using Snomax ${ }^{\circledR}$ as test substance, Atmos. Chem. Phys., 15, 1463 1485, doi:10.5194/acp-15-1463-2015, 2015.

Wood, S. E., Baker, M. B., and Swanson, B. D.: Instrument for studies of homogeneous and heterogeneous ice nucleation in freefalling supercooled water droplets, Rev. Sci. Instrum., 73, 3988, doi:10.1063/1.1511796, 2002.

Wright, T. P. and Petters, M. D.: The role of time in heterogeneous freezing nucleation, J. Geophys. Res. Atmos., 118, 3731-3743, doi:10.1002/jgrd.50365, 2013.

Yankofsky, S. A., Levin, Z., Bertold, T., and Sandlerman, N.: Some basic characteristics of bacterial freezing nuclei, J. Appl. Meteorol., 20, 1013-1019, doi:10.1175/15200450(1981)020<1013:SBCOBF>2.0.CO;2, 1981.

Zobrist, B., Koop, T., Luo, B., Marcolli, C., and Peter, T.: Heterogeneous ice nucleation rate coefficient of water droplets coated by a nonadecanol monolayer, J. Phys. Chem. C, 111, 2149-2155, doi:10.1021/jp066080w, 2007. 